LOCAL WISDOM, $\mathbf{9}(\mathbf{1}): \mathbf{9 0}-\mathbf{1 0 2 , 2 0 1 7}$
Local Wisdom Scientific Online Journal
ISSN: 2086-3764

\title{
Filosofi Hidup sebagai Wujud Kearifan Lokal Masyarakat Adat Kasepuhan Sinar Resmi
}

\author{
Sari Mawaddahni ${ }^{*}$ \\ 1 Program Magister Arsitektur Lingkungan Binaan Fakultas Teknik \\ Universitas Brawijaya \\ *dahni.313@gmail.com
}

\begin{abstract}
Abstrak
Kata kunci: kasepuhan, filosofi hidup, kearifan lokal

Kasepuhan Sinar Resmi merupakan masyarakat adat yang tinggal di kawasan Taman Nasional Gunung Halimun Salak (TNGHS), di wilayah kabupaten Sukabumi, Jawa Barat. Aturan adat leluhur menjadi bagian yang tidak terpisahkan dalam kehidupan keseharian masyarakat kasepuhan. Sebagai masyarakat peladang, masyarakat kasepuhan taat terhadap aturan leluhur dengan menjalankan berbagai ritual tradisi yang menyangkut kegiatan pertanian. Filosofi hidup yang sederhana, menghargai serta menyatu dengan alam merupakan wujud kearifan lokal yang dipegang teguh oleh masyarakat kasepuhan. Derasnya arus perkembangan teknologi dan informasi dikhawatirkan akan memberikan dampak negatif pada keberlanjutan nilai-nilai tradisi pada kehidupan masyarakat kasepuhan. Kajian terhadap objek studi dilakukan untuk mengidentifikasi potensi-potensi nilai kearifan lokal yang dimiliki oleh masyarakat kasepuhan Sinar Resmi. Untuk mengkaji nilai-nilai kearifan lokal pada kasepuhan Sinar Resmi, digunakan metode deskriptifkualitatif dengan menganalisa dan mengumpulkan literasi data sekunder.

\section{Abstract}

Keyword:

kasepuhan, philosophy of life, local wisdom

Kasepuhan Sinar Resmi are indiheneous people that settled in the area of National Park of Halimun Salak Mountain, on Kabupaten Sukabumi, West Java. The customs and tradition from the ancestors being unseparatable part on the community's life. As a farming community, the people of kasepuhan obey the ancestral rules by carried out the ritual tradition, especially those related in farming activity. Live in humble and respect nature are their philosophy of life that became the local wisdom and adhered to the kasepuhan people. The rapid flow of technology and information have an impact on the continuity of the local values. The aim of the study are to identify the potencies of Kasepuhan Sinar Resmi's local wisdom. The method used is descriptive-qualitative by analyzing secondary data from the gathered literature.
\end{abstract}




\section{PENDAHULUAN}

Indonesia merupakan negara yang terdiri dari 17.504 pulau dengan 633 kelompok suku besar yang dapat dibagi menjadi 1.331 suku (termasuk sub suku, sub sub-suku dan nama alias) ${ }^{1,2}$. Dengan banyaknya jumlah suku dan pulau, Indonesia menjadi negara yang kaya akan ragam budaya. Sukusuku tersebut tinggal secara tersebar di seluruh wilayah Indonesia, baik di pulau kecil serta besar, di daerah pesisir laut, dataran hingga pegunungan. Kebudayaan Indonesia terbentuk melalui proses yang sangat panjang dan dalam jangka waktu yang lama. Unsur-unsur budaya yang tumbuh dan berkembang di tengah kehidupan masyarakat antara lain agama, bahasa, norma, pengetahuan, ekonomi, kesenian, peralatan hidup, serta budaya bermukim ${ }^{3}$. Diversitas suku maupun masyarakat adat beserta permukimannya menjadi khasanah budaya Indonesia yang harus dijaga keberlanjutannya. Teknologi dan informasi yang terus berkembang, menyebabkan terjadinya pergeseran nilai budaya leluhur yang diwariskan untuk generasi penerusnya.

Kasepuhan Sinar Resmi, merupakan salah satu masyarakat adat yang tinggal di kawasan Taman Nasional Gunung Halimun Salak (TNGHS), Jawa Barat. Tatali paranti karuhun menjadi dasar budaya masyarakat kasepuhan untuk tetap mempertahankan kearifan lokal sebagai implementasi filosofi hidupnya dalam bentuk religi, pandangan hidup, mata pencaharian dan aktivitas sosial budaya yang berjalan dari generasi satu ke generasi selanjutnya.

Tujuan dari kajian ini adalah: 1) Mengidentifikasi filosofi hidup dan sistem sosial budaya pada masyarakat Kasepuhan Sinar Resmi; 2) Mengidentifikasi kearifan lokal masyarakat Kasepuhan Sinar Resmi serta implementasinya dalam kehidupan keseharian.

Hasil dari kajian ini diharapkan dapat memberikan manfaat berupa: 1) Pemahaman filosofi hidup sebagai dasar kearifan lokal masyarakat; 2)
Sebagai pertimbangan dalam penentuan kebijakan yang berkaitan dengan masyarakat adat.

\section{METODE}

Kajian dilakukan dengan analisa secara deskriptif-kualitatif untuk mendapatkan pandanganpandangan dan makna kearifan lokal masyarakat kasepuhan. Data sekunder diperoleh melalui literasi pustaka maupun video wawancara mengenai tema dan lokasi studi yang terkait.

\section{MAKNA KEARIFAN LOKAL}

Permana menyebutkan adanya keterkaian antara kearifan lokal dengan masyarakat lokal, dan dalam bahasa asing disebut sebagai local wisdom (kebijakan setempat), local knowledge (pengetahuan setempat), atau local genius (kecerdasan setempat). Pandangan hidup, pengetahuan serta berbagai strategi kehidupan yang berwujud aktivitas yang dilakukan oleh masyarakat lokal dalam menjawab berbagai masalah dalam pemenuhan kebutuhan mereka, meliputi seluruh unsur kehidupan; agama, ilmu dan teknologi, organisasi sosial, bahasa dan komunikasi, serta kesenian merupakan wujud kearifan lokal. Masyarakatnya memiliki pemahaman, program, kegiatan, pelaksanaan terkait untuk memper-tahankan, memperbaiki, dan mengembangkan unsur kebutuhan dan cara pemenuhannya, dengan memper-hatikan sumber daya manusia dan sumber daya alam di sekitarnya ${ }^{4}$.

Lebih lanjut, Permana menyebutkan bahwa kearifan lokal memiliki enam dimensi, yaitu: [1] Dimensi pengetahuan lokal; [2] Dimensi nilai lokal; [3] Dimensi keterampilan lokal sebagai kemampuan bertahan hidup (survival). Keterampilan lokal biasanya hanya cukup dan mampu memenuhi kebutuhan keluarganya masing-masing atau disebut dengan ekonomi subsistensi; [4] Dimensi sumberdaya lokal, penggunaannya sesuai dengan kebutuhan, tidak melakukan eksploitasi secara besar- 


\section{Kearifan Lokal Masyarakat Kampung Wisata Kerajinan Tangan di Dusun Rejoso Kota Batu}

Baskoro Azis

besaran atau dikomersialkan. Terdapat pembagian wilayah seperti hutan, kebun, sumber air, lahan pertanian, dan permukiman, dan kepemilikan sumberdaya lokal bersifat kolektif. [5] Dimensi mekanisme pengambilan keputusan lokal. Setiap masyarakat pada dasarnya memiliki pemerintahan lokal sendiri atau disebut pemerintahan kesukuan; [6] Dimensi solidaritas kelompok lokal. Suatu masyarakat umumnya dipersatukan oleh ikatan komunal, ikatan komunikasi untuk membentuk solidaritas lokal. Setiap masyarakat mempunyai media-media untuk mengikat warganya yang dapat dilakukan melalui ritual keagamaan atau acara dan upacara adat lainnya ${ }^{4}$.

Dalam kearifan lokal terwujud upaya pengelolaan dan konservasi sumberdaya alam dan lingkungan. Nababan mengemukakan prinsip-prinsip pengelolaan dan konservasi sumberdaya alam secara tradisional meliputi: [1] Rasa hormat yang mendorong keselarasan hubungan manusia dengan alam sekitarnya. Masyarakat tradisional cenderung memandang dirinya sebagai bagian dari alam, [2] Rasa memiliki yang eksklusif bagi komunitas atas suatu kawasan atau jenis sumberdaya alam tertentu sebagai hak kepemilikan bersama (communal property resource), [3] Sistem pengetahuan masyarakat setempat memberikan kemampuan kepada masyarakat untuk memecahkan masalah dalam memanfaatkan sumberdaya alam yang terbatas, [4] Daya adaptasi dalam penggunaan teknologi sederhana yang tepat guna dan hemat energi sesuai dengan kondisi alam setempat, [5] Sistem alokasi dan penegakan aturan-aturan adat yang bisa mengamankan sumberdaya milik bersama dari penggunaan berlebihan, baik oleh masyarakat sendiri maupun oleh masyarakat luar (pendatang), [6] Mekanisme pemerataan (distribusi) hasil panen atau sumber daya milik bersama yang dapat mencegah munculnya kesenjangan dalam masyarakat ${ }^{4}$. Keteraturan sosial mencegah terjadinya pelanggaran terhadap aturan adat yang berlaku dalam masyarakat.

\section{A. Definisi Masyarakat Adat}

Hazairing mendefinisikan masyarakat adat sebagai sebuah kesatuan hukum, kesatuan penguasa dan kesatuan lingkungan hidup berdasarkan hak bersama atas tanah dan air bagi semua warganya ${ }^{5}$. Hal ini sejalan dengan pendapat dari Aliansi Masyarakat Adat Nusantara (AMAN) dalam draf RUU Pengakuan dan Perlindungan Masyarakat Adat, dengan menambahkan faktor asal-usul leluhur secara turun temurun pada wilayah geografis tertentu, serta memiliki sistem nilai, ideologi, ekonomi, politik, budaya, sosial dan wilayah sendiri ${ }^{6}$. Masyarakat adat dapat disebut juga sebagai masyarakat tradisional, dengan mencirikan adanya: [1] Ikatan yang erat antara masyarakat dengan lingkungan, [2] Sikap hidup dan tingkah laku yang magis religius, [3] Adanya kehidupan gotongroyong, [4] Memegang tradisi dengan kuat, [5] Menghormati para sesepuh, [6] Kepercayaan pada pimpinan lokal dan tradisional, [7] Organisasi kemasyarakatan yang relatif statis, dan [8] Nilai sosial yang tinggi ${ }^{7}$.

\section{B. Permukiman Sebagai Wujud Sosial- Budaya}

Altman mengartikan lingkungan sebagai rona (setting) fisik yang menjadi tempat manusia melaksanakan kehidupan dan kebudayaannya. Arti lingkungan di sini lebih pada kondisi fisik alam dan buatan. Dengan menempatkan arsitektur sebagai benda fisik buatan manusia dari produk budaya material, maka terdapat interaksi (hubungan) dialogis antar keduanya ${ }^{8}$. Sedangkan Habraken menjelaskan bahwa tatanan fisik permukiman merupakan satu kesatuan sistem yang terdiri dari: spatial system, physical system dan stylistic system. Spatial system, yaitu sistem yang berkaitan dengan organisasi ruang, mencakup: hubungan ruang, orientasi, pola hubungan ruang dan sebagainya. Physical system, yaitu sistem mengenai penggunaan konstruksi dan material, sedangkan stylistic sys- 


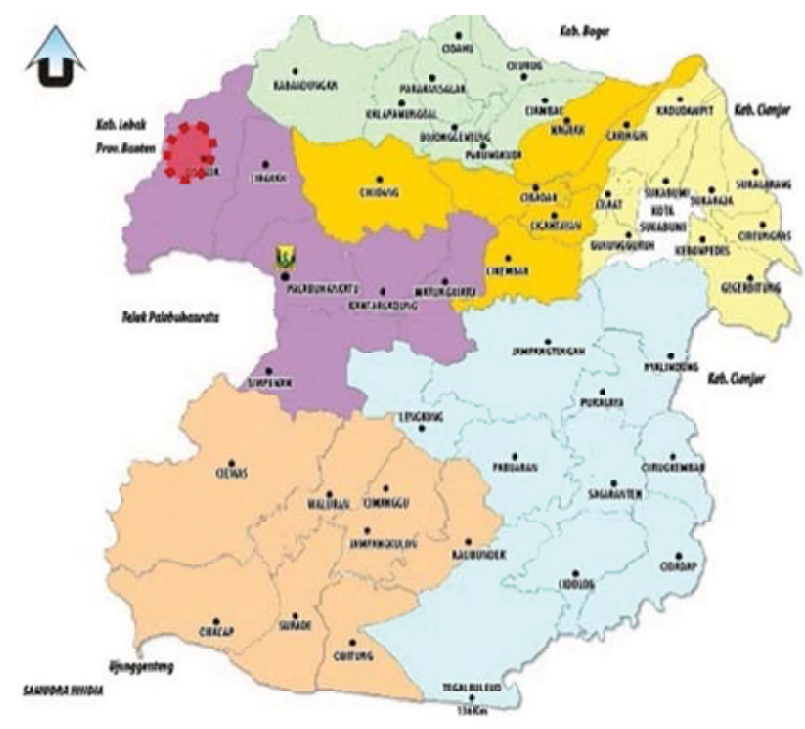

Gambar 1 Peta Kabupaten Sukabumi (Sumber: www.peta-kota.blogspot.co.id, 2016)

tem merupakan kesatuan yang mewujudkan bentuk meliputi: fasad atau muka bangunan, bentuk pintu dan jendela serta unsur-unsur ragam hias (craftmanship), baik di dalam maupun di luar9.

\section{Pembahasan}

\section{Kondisi Geografis Desa Sirna Resmi}

Batas wilayah:

- Sebelah utara : Sungai Cibareno

- Sebelah Selatan : Dusun Cibongbong

- Sebelah Timur : Dusun Cikaret

- Sebelah Barat : Desa Cicadas

Kawasan Taman Nasional Gunung Halimun Salak (TNGHS) merupakan kawasan hujan tropis alam terbesar di Jawa Barat - Banten. Ada 15 kasepuhan yang bermukim di kawasan TNGHS, disebut sebagai Kasepuhan Banten Kidul dengan cakupan wilayah meliputi Sukabumi Selatan, Bogor Selatan dan Lebak ${ }^{10}$. Kasepuhan menunjuk pada

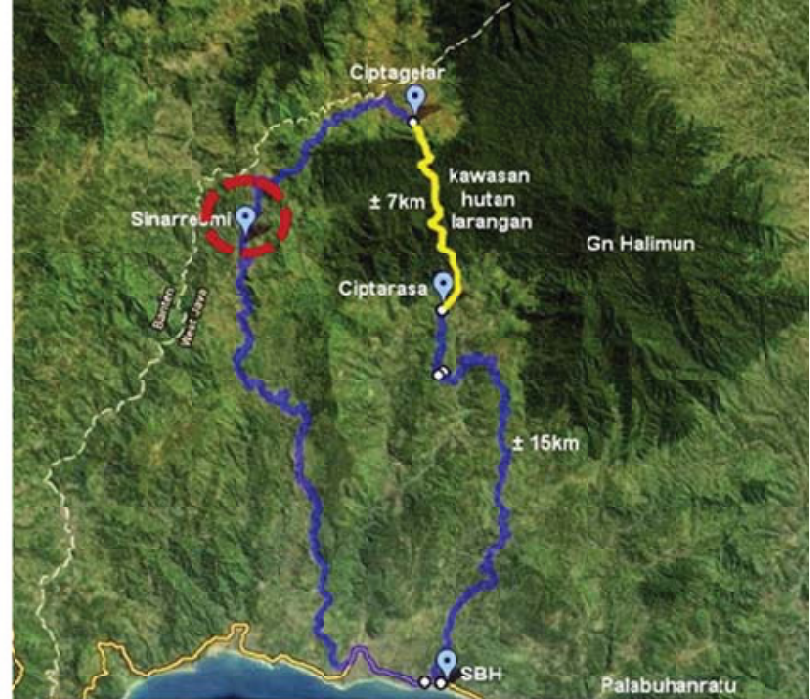

Gambar 2. Peta Kasepuhan Banten Kidul (Sumber: www.budaya-sukabumi.blogspot.co.id, 2016)

adat istiadat lama yang masih dipertahankan dalam kehidupan sehari-hari. Kasepuhan merupakan suatu himpun-an dari banyak lembur (permukiman) dan kampung-kampung kecil dan besar yang terikat secara adat dan budaya ${ }^{11}$. Dari segi sosiobudaya, karakteristik masyarakatnya menyerupai budaya Sunda abad ke-16 ${ }^{12}$.

Masyarakat kasepuhan Banten Kidul berada di Desa Sirna Resmi, Kecamatan Cisolok, Kabupaten Sukabumi, Propinsi Jawa Barat. Secara geografis desa ini terletak antara $106^{\circ} 27^{\prime}-106^{\circ} 33^{\prime}$ BT dan $6^{\circ} 52^{\prime}-6^{\circ} 44^{\prime}$ LS dengan luas wilayah 4.917

Ha. Desa Sirna Resmi berada pada rangkaian pegunungan vulkanis gunung Halimun, bagian dari rantai Bukit Barisan di Pulau Sumatera dan gunung api pulau Jawa bagian barat. Morfologi TNGHS bergelombang sampai berbukit dengan kemiringan $21 \%$ - $45 \%$ sehingga warga kasepuhan mengupaya-kan penyangga erosi dalam bentuk sengkedan (terasering) dan tanaman pelindung seperti bambu, pisang dan aren yang berakar serabut serta pohon jeungjing bodas (sengon). 
Kondisi iklim termasuk tipe A (Iklim hujan tropis) dengan curah hujan tahunan sebesar 3.500$4.500 \mathrm{~mm} /$ tahun. Rata-rata curah hujan bulanan > $100 \mathrm{~mm}$, dengan bulan terkering (+200 mm) pada Juni sampai September dan terbasah (+550 mm) antara Oktober dan Maret, sehingga dapat digolongkan beriklim selalu basah, kelembaban udara rata-rata $88 \%$. Suhu rata-rata bulanan $22,50^{\circ} \mathrm{C}$ dengan suhu terendah $19,7^{\circ} \mathrm{C}$ dan suhu tertinggi $31,8^{\circ} \mathrm{C}$. Kondisi tersebut mendukung ekosistem kawasan TNGHS sehingga terdapat flora dan fauna yang beragam ${ }^{10}$.

\section{A. Filosofi Hidup}

Filosofi hidup masyarakat Kasepuhan Sinar Resmi adalah sebagai Pancer pangawinan, yaitu mempersatukan manusa jeung kemanusaanna (manusia dengan kemanusiaannya), dan menjadi dasar dalam tindakan sehari-hari yang disebut ngaji diri (mawas diri) atau memahami diri sendiri. Bersikap mawas diri artinya selalu berhati-hati dalam bersikap dan berbicara terhadap sesama manusia. Ngaji diri menjadi pilar kehidupan masyarakat dalam membina hubungan antar sesama masyarakat kasepuhan, yakni dalam tekad, ucap jeung lampah (kemauan/ niat, perkataan dan perilaku). Niat merupakan titik awal dalam melakukan sesuatu yang tercermin dalam perkataan dan perilaku seseorang, sehingga ketidaksesuaian antar ketiganya menimbul-kan perilaku munafik. Dalam berucap harus selalu sopan dan berhati-hati, 'saur kedah diukur, nyabda kedah diuger' agar tidak menimbulkan salah paham dan menyinggung perasaan orang lain ${ }^{13}$.

Masyarakat kasepuhan sangat bergantung pada sumberdaya alam di sekitarnya. Dalam istilah 'mipit kudu amit ngala kudu menta', masyarakat diwajibkan untuk memohon izin, yang diawali dengan doa untuk meminta keberkahan, keselamatan dan keberhasilan saat memetik atau memanen di huma atau sawahnya. 'Ngereut jeung neundeun keur jaga ning isuk' bermakna menyisihkan untuk hari depan, sehingga akan berkecukupan di masa mendatang. Hal ini diwujudkan dalam bentuk leuit atau lumbung padi yang wajib dimiliki oelh setiap masyarakat kasepuhan. 'Saeutik, mahi loba nyesa halal didaharna' artinya sedikit ataupun cukup banyak hasil panen, harus menyisakan dan halal dimakan. Ungkapan-ungkapan tersebut mengandung makna bahwa masyarakat kasepuhan memiliki sikap hidup bersahaja dan sederhana, dengan pemuas kebutuhan yang terbatas harus dapat mencukupi kebutuhan hidup, namun saat memiliki kelebihan materi harus menyisihkan serta mendapatkan sesuatu harus dengan cara yang halal ${ }^{13}$.

\section{B. Sosial-Budaya Kasepuhan Banten Kidul}

Makna yang tersirat dari sebuah kasepuhan adalah adanya pelestarian dari nilai-nilai tradisi yang diwariskan oleh nenek moyang, dalam masyarakat kasepuhan disebut sebagai tatali paranti karuhun. Sebuah kasepuhan dipimpin oleh tutunggul yang ditunjuk berdasarkan petunjuk gaib (wangsit) dari tutunggul sebelumnya. Ketua kasepuhan tidak boleh menjabat dalam struktur pemerintahan desa agar tidak terjadi kerancuan dalam melestarikan tatali paranti karuhun. Incu putu (keturunan) masyarakat adat Kasepuhan Banten Kidul tersebar di berbagai wilayah di Sukabumi, Bogor, Lebak, Banten Selatan, Bandung, Jakarta, Cirebon, Kuningan maupun di beberapa kota di luar Jawa.

Jumlah incu putu tiap tahun dapat berbeda, karena setiap warga dapat memiliki keyakinan akan kasepuhan yang dituakan. Sebagai contoh, warga hidup di lingkungan Kasepuhan Sinar Resmi, tetapi menuakan Kasepuhan Ciptagelar. Mereka beranggapan bahwa kesemuanya merupa-kan baris kolot Kesatuan Masyarakat Adat Banten Kidul keturunan Pancer pangawinan. 
LOCAL WISDOM, Vol. 9 No. 2 Juli 2017

Local Wisdom Scientific Online Journal

Tabel 1. Jabatan dan Tugas Dalam Lembaga Adat

\begin{tabular}{ll}
\hline Jabatan & Tugas \\
\hline Tutunggul & Memimpin kasepuhan \\
\hline Sabah (penasehat) & Memberikan nasehat pada Tutunggul Lembur \\
\hline Girang Serat & Bertugas mengatur keperluan/acara adat \\
\hline Bendahara & Mengatur keuangan kasepuhan \\
\hline Dukun & Mengobati orang sakit dan mencegah wabah \\
\hline Ma Beurang & Menolong ibu melahirkan \\
\hline Cancli Padaringan & $\begin{array}{l}\text { Mengambil beras dari tempat penyimpanan beras untuk dimasak pada acara adat } \\
\text { terutama selamatan dan juga membantu untuk memasaknya }\end{array}$ \\
\hline Bengkong & Mengkhitan anak-anak \\
\hline Paninggaran & Melakukan perburuan \\
\hline Panghulu & Memimpin do'a saat kegiatan adat dilaksanakan \\
\hline Juru Pamakayaan & Mengatur kegiatan pertanian, di sawah dan di huma \\
Tani & Memimpin kampung/dusun \\
\hline Kolot Lembur &
\end{tabular}

Sumber: Ningrat, 2004

Kasepuhan Banten Kidul merupakan sebuah lembaga adat yang memiliki struktur lembaga dimana masing-masing fungsi memiliki tugas sesuai dengan aturan adat istiadat yang telah dijalankan secara turun temurun. Abah selaku ketua kasepuhan menggunakan lembaga adat dalam menata hubungan yang stabil antara sesama warga (keselarasan sosial), serta antara masyarakat dengan alam dan lingkungan (keselarasan alam) yang merupakan sumber kehidupan utama. Dengan demikian, akan tercipta perilaku arif dalam lingkungan sosial, menjaga alam dan lingkungan serta kerukunan antar masyarakat.

Masyarakat kasepuhan Sinar Resmi merupakan masyarakat yang terbuka terhadap dunia luar serta kehidupan modern. Hal ini sejalan dengan mulai berkembangnya akses jalan yang lebih mudah, listrik dan sarana komunikasi yang telah menjangkau permukiman warga. Masyarakat juga menjunjung tinggi hukum dan peraturan negara, yang tercermin pada pemakaian ikat kepala bagi kaum laki-laki. Ikat kepala menggunakan kain segiempat yang merupakan lambang dari empat arah mata angin. Kain dilipat menjadi bentuk segitiga, melambangkan tiga hukum (adat, negara dan agama). Dalam setiap pemilihan baik tingkat daerah maupun negara, masyarakat selalu berpartisipasi.

\section{Implementasi Sosial-Budaya Pada Permukiman}

Tata ruang spasial pada permukiman kasepuhan Sinar Resmi dikategorikan menjadi: [1] Pola dan orientasi permukiman (makro); [2] Hubungan antar bangunan (meso); [3] Hubungan antar ruang (mikro). Batas, secara tidak langsung menjadi tameng bagi aktivitas penghuni di dalamnya. Di samping itu, batas juga memiliki makna kesadaran untuk menghormati hak-hak tetangga di sekitarnya, artinya mereka akan merasa aman dan tenang apabila berada dalam lingkungan komunitasnya. Batas pada permukiman kasepuhan terbagi menjadi dua, yakni batas fisik dan batas non fisik. Batas fisik pada permukiman kasepuhan Sinar Resmi berupa sungai, hutan, sawah kebun, bukit, talun, maupun pagar bambu. Sedangkan yang menjadi batas non fisik berhubungan dengan kepercayaan warga terhadap hal-hal yang tidak kasat mata. Batas non fisik sulit untuk dibuktikan, karena ber- 


\section{Kearifan Lokal Masyarakat Kampung Wisata Kerajinan Tangan di Dusun Rejoso Kota Batu}

Baskoro Azis

kaitan dengan keyakinan warga, tetapi dapat dirasakan seperti: takut, angker, menyeramkan dan lain-lain. Tempat-tempat yang jarang atau tidak pernah dimasuki oleh manusia dipercaya memiliki kekuatan jahat, seperti leuweung tutupan, makam dan pohon besar. Kepercayaan warga terhadap roh-roh halus, secara tidak langsung menjadi batas permukiman dan merupakan bukti pengakuan mereka akan eksistensi serta hubungan erat antara yang kasat mata dengan yang tidak kasat mata. Hubungan tersebut terlihat pada pelaksanaan berbagai upacara ritual dan pemberian sesajen dengan tujuan untuk menghormati atau mengharap berkah. Menurut Adimihardja, hal tersebut merupakan ciri masyarakat tradisional yang masih mempercayai larangan, seperti adanya makhluk-makhluk atau wujud-wujud yang sakral, bersifat gaib, tidak dapat dibuktikan secara eksperimental tentang keberada-annya, karena bagi yang tidak tahu dan tidak percaya menganggap hal itu tidak ada. Namun bagi yang mempercayainya perasaan kagum dan tunduk pada objek-objek yang disakralkan tetap menjadi landasan hubungan dengan yang disakralkan ${ }^{12}$.

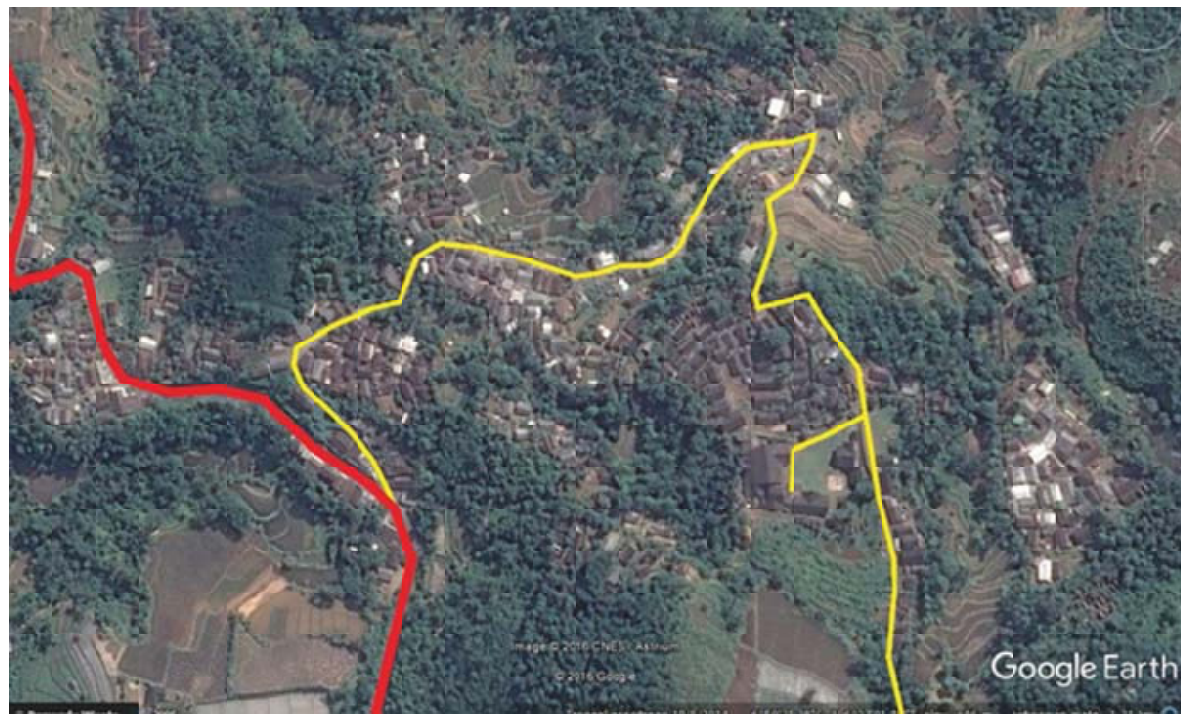

Gambar 3. Pola Tata Massa Bangunan Pada Kampung Kasepuhan Sinar Resmi (Sumber: Google Earth, 2016) Pola Dan Orientasi Permukiman (Makro)

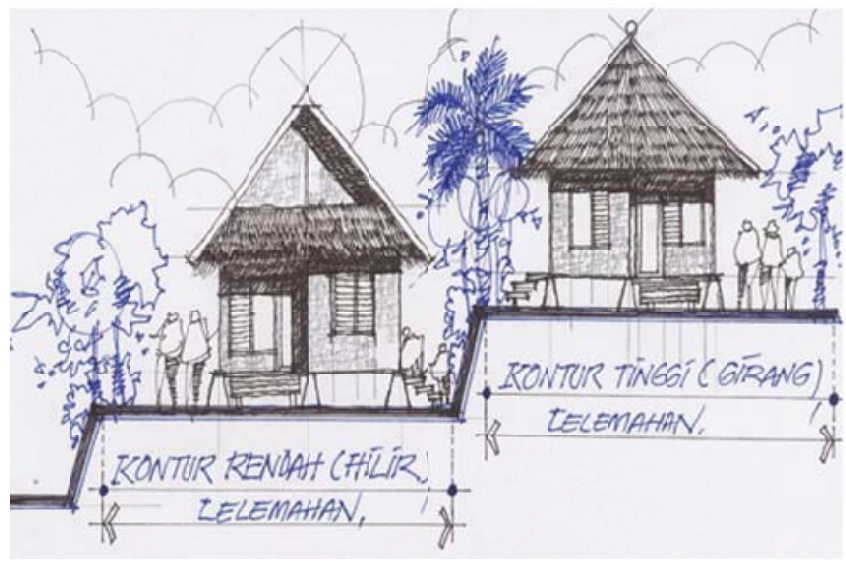

Gambar 4. Posisi Bumi Ageung Terhadap Rumah Warga (Sumber: Nuryanto \& Widaningsih, 2008)

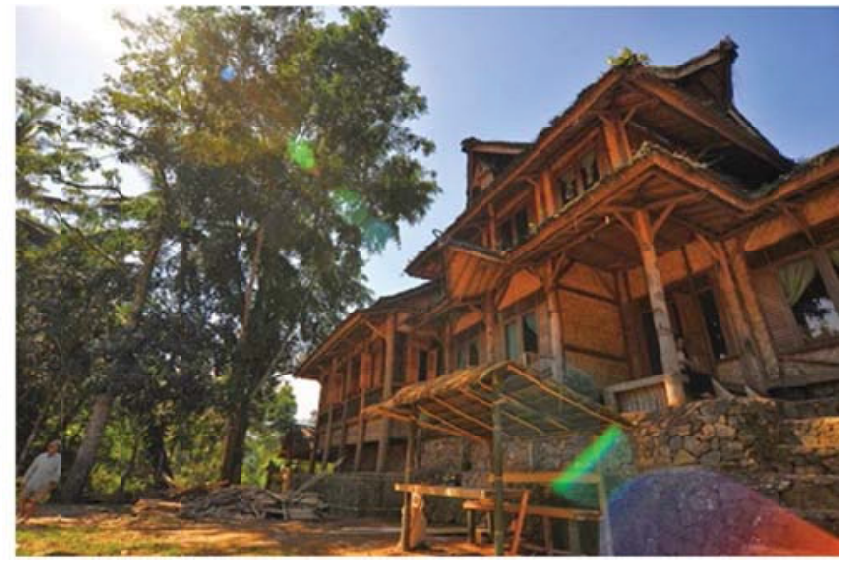

Gambar 5. Bumi Ageung Kasepuhan Sinar Resmi (Sumber: Google Images, 2016) 
Berdasarkan letak geografisnya yang berada di kaki pegunungan di kawasan Taman Nasional Gunung Halimun Salak (TNGHS), kampung kasepuhan Sinar Resmi termasuk dalam kampung pegunungan. Sedangkan berdasarkan mata pencaharian, dalam hal ini merupakan basis kehidupan masyarakat kasepuhan Sinar Resmi, maka dikategorikan sebagai kampung pertanian. Ditinjau dari sudut pengelompokan bangunannya, seperti: rumah tinggal, lumbung padi, tempat menumbuk padi, kandang ternak, bale desa, musholla, bale adat dan lain-lain, pola massa bangunan di kampung kasepuhan Sinar Resmi adalah pola linier dan menyebar. Pola linier terdapat pada bangunan yang berhadapan dengan jalan, sedangkan untuk bangunan-bangunan yang terdapat di belakang rumah tersebut tata massanya mengikuti kontur lahan sehingga terkesan tidak beraturan. Bangunanbangunan yang berhadapan dengan jalan ditata secara linier mengikuti alur jalan pada kampung. Sedangkan bangunan-bangunan di belakangnya, memiliki pola memusat dengan bumi ageung (rumah ketua kasepuhan) sebagai orientasinya.

Tata ruang bumi ageung disebut juga dengan istilah daerah girang (paling tinggi), sedangkan bumi warga dikenal dengan sebutan daerah hilir, karena posisinya di bawah girang. Pembagian girang dan hilir didasarkan pada dua alasan, pertama: girang merupakan tempat kedudukan (tempat tinggal) pimpinan adat yang harus dihormati, sedangkan hilir merupakan tempat kedudukan warga kasepuhan yang harus tunduk dan patuh pada pimpinannya. Kedua, berdasarkan pada kontur tanah yang tidak rata.

Pada tata ruang secara makro dan meso, bumi ageung harus diletakkan pada sumbu utara-selatan, atau bagian depannya menghadap ke selatan. Dalam pandangan warga, selatan atau kidul dipercaya sebagai tempat ngancikna atau bersemayamnya Nyi Sri Pohaci (Dewi Padi) yang setiap saat 'memberikan' kesuburan pangan bagi warga

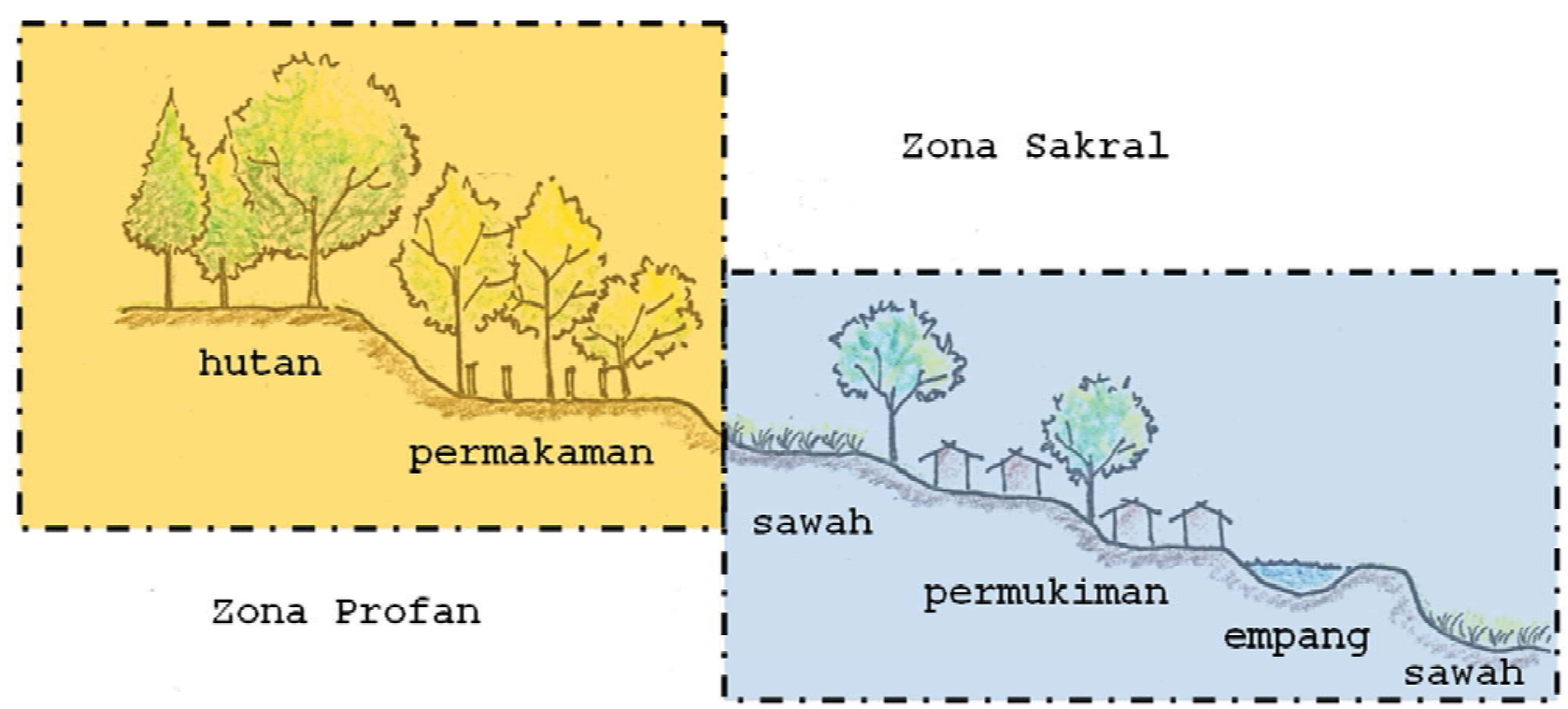

Gambar 6. Pola Tata Massa Pada Kampung Kasepuhan Sinar Resmi Berdasarkan Kontur Lahan (Sumber: Hasil Analisis, 2016) 
kasepuhan. Arah selatan juga memiliki makna ka indung (ibu) sedangkan utara ka bapa (bapak). Hal ini merupakan perwujudan makna bahawa setiap anak harus menghormati kedua orang tuanya sesuai peribahasa: "indung tunggulna rahayu, bapa tangkalna darajat", artinya ibu sumber kesejahteraan dan bapak sumber keselamatan.

Secara makro, makam berada di tempat yang tinggi berdekatan dengan hutan, dengan orientasi barat-timur. Hal ini berkaitan dengan pandangan masyarakat kasepuhan, barat sebagai simbol kabinasaan (kematian) dan timur sebagai simbol kahirupan (kehidupan). Barat atau kulon merupakan tempat surupna panon poe atau batara surya (terbenamnya matahari), sedangkan timur atau wetan merupakan tempat bijilna panon poe (terbitnya matahari).

Secara makro, terbentuk ruang sakral dan profan pada kampung kasepuhan Sinar Resmi. Hutan dan makam merupakan ruang sakral, sedangkan permukiman merupakan ruang profan. Posisi ketinggian menjadi batas secara fisik antara ruang sakral dengan profan, dan kepercayaan dan kepatuhan warga terhadap larangan untuk memasuki hutan menjadai batas non fisik. Makam menjadi area yang sakral karena sebelum memulai sebuah ritual tradisi, misalnya seren taun. Warga mendatangi makam leluhur untuk memohon restu agar apa yang diharapkan dapat berjalan lancar sesuai harapan.

\section{Hubungan Antar Bangunan (Meso)}

Pada kampung kasepuhan Sinar Resmi, masing-masing bangunan memiliki fungsi tertentu. Berdasarkan fungsi publik-privat, bangunanbangunan pada kampung kasepuhan Sinar Resmi dapat dibagi sesuai bagan pada gambar 6. Berdasarkan gender pelaku, bangunan yang boleh diakses ditunjukkan sesuai bagan pada gambar 7 . makna manusa ka Gustina: "usik malikna manusa ukur

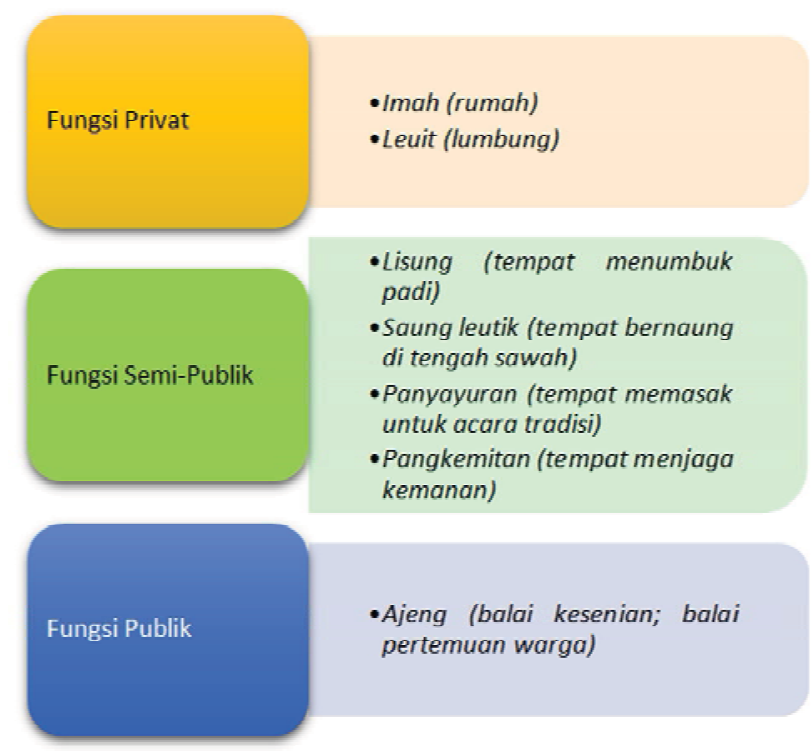

Gambar 7. Fungsi Publik - Privat Pada Bangunan di Kawasan Permukiman (Sumber: Hasil Analisa, 2016)

\section{E. Hubungan Antar Ruang (Mikro)}

Bentuk rumah panggung dalam pandangan masyarakat kasepuhan dipercaya sebagai simbol tangtungan jelema (tubuh manusia) yang terdiri dari 3 (tiga) bagian utama: suku, awak dan hulu. Suku yaitu kaki menyimbolkan pondasi, awak merupakan badan melambangkan dinding dan lantai, sedangkan hulu adalah kepala sebagai simbol atap. Bagian suku memiliki makna kabinasaan: "hiji mangsa urang bakal tinemu ajal, numatak kudu inget", artinya suatu saat kita akan mati, oleh karena itu harus ingat pada kematian: "hirup ka ukur ku tangtung, paeh teu nyaho di mangsa", artinya hidup manusia seumur tubuhnya, sedangkan kematian tidak mengenal waktu dan tempat. Bagian awak mengandung makna kahirupan: "gumelarna manusa keur hirup jeung kahirupannana", artinya manusia lahir di dunia untuk hidup dan kehidupannya. Bagian hulu memiliki 
Gusti nu kagungan". Rumah masyarakat kasepuhan harus memiliki tiga ruang penting yaitu pangdaringan, hawu, dan sepen.

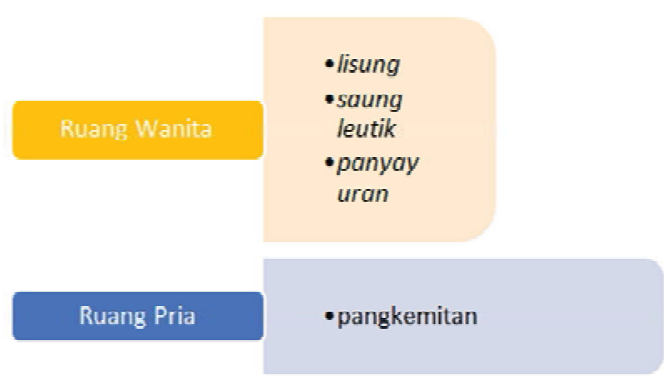

Gambar 8. Aksesibilitas Pengguna Bangunan Berdasarkan Gender

(Sumber: Hasil Analisa, 2016) a. Pangdaringan, berbentuk segi empat, terbuat dari bahan kayu, dan ditutupi tirai 'kasang' (pintu dari kayu)

b. Hawu, berbentuk segi empat, dibuat dari bahan semen yang dicetak dan dilubangi di bagian tengahnya agar api dapat bekerja dengan baik. Letaknya di goah (dapur) dan di atasnya terdapat rak dari kayu untuk meletakkan perlengkapan dapur maupun bibit dan alat pertanian.

c. Sepen, berfungsi sebagai ruang tidur, dibatasi dengan dinding kayu dengan 'kasang' sebagai tirai.

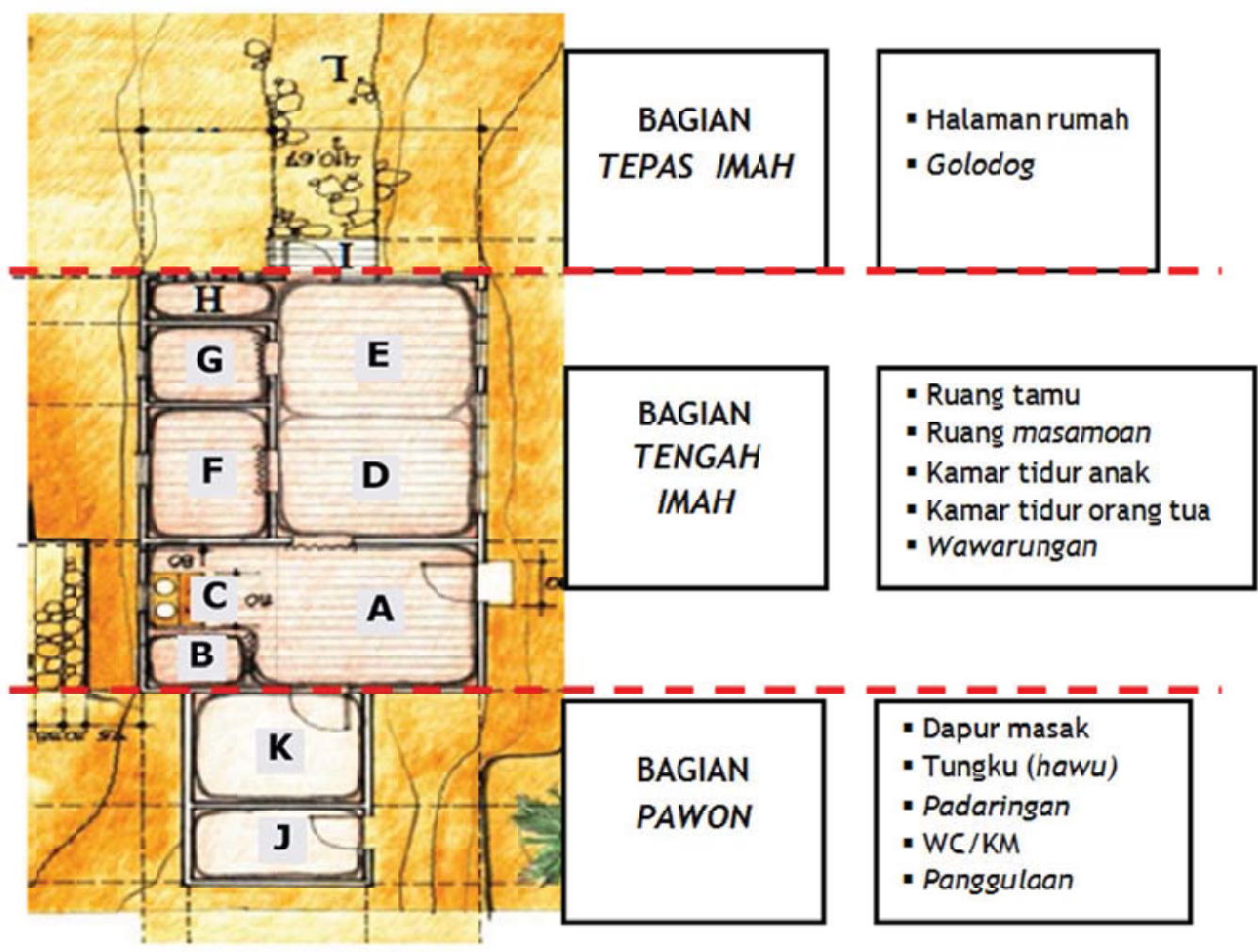

Keterangan huruf pada gambar:

\begin{tabular}{|l|l|l|l|l|l|}
\hline A. & Pawon (dapur) & E. & Ruang tamu & I. & Golodog \\
\hline B. & Padaningan & F. & Pangkeng orang tua & J. & Panggulaan \\
\hline C. & Hawu & G. & Pangkeng anak & K. & WC/KM \\
\hline D. & Ruang masamoan & H. & Wawarungan & L. & Buruan imah \\
\hline
\end{tabular}

Gambar 9. Pola Tata Ruang Pada Rumah Tinggal (Sumber:Nuryanto \& Widaningsih, 2008) 


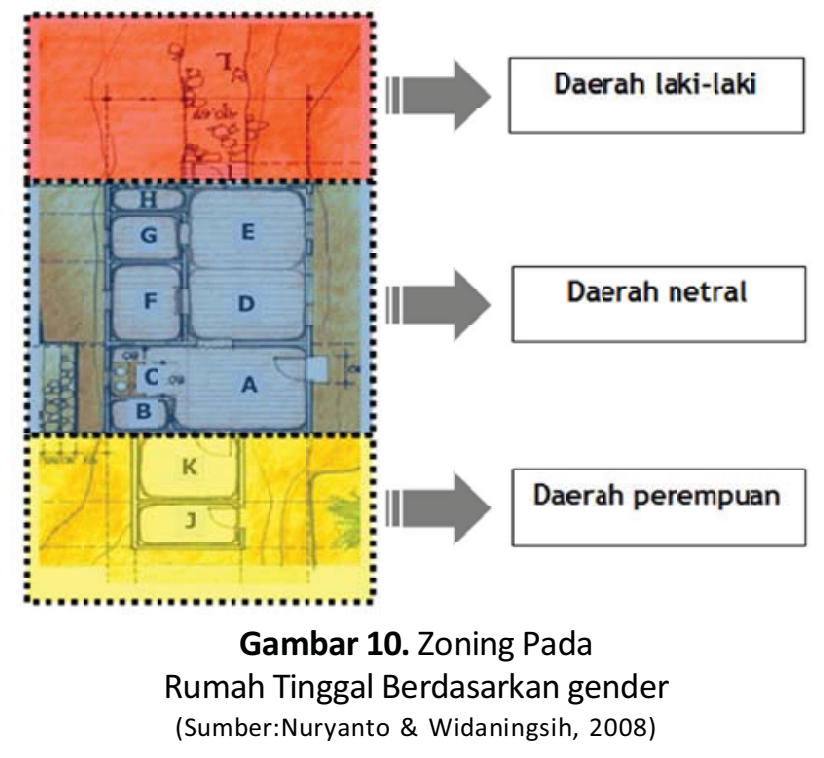

Organisasi ruang pada rumah panggung terdiri dari 3 (tiga): tepas imah, tengah imah dan pawon. Tepas imah (depan) merupakan daerah laki-laki, karena aktifitasnya cenderung dilakukan oleh lakilaki, tengah imah (tengah) menjadi daerah umum, karena laki-laki dan perempuan dapat melakukan aktifitas bersama-sama, sedangkan pawon (belakang) merupakan daerah perempuan, karena seluruh aktifitasnya dilakukan oleh perempuan.

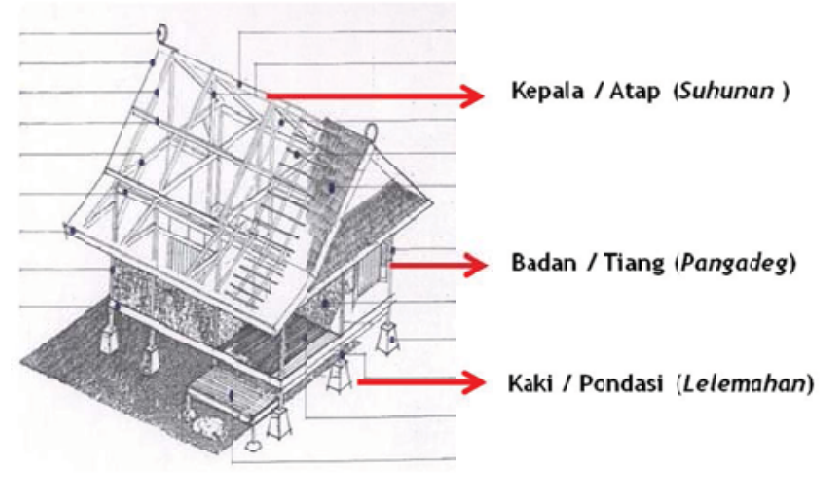

Gambar 11. Simbolisme Pada Struktur Bangunan (Sumber: Nuryanto \& Widaningsih, 2008)

Pembagian daerah laki-laki dan perempuan tersebut didasarkan pada fungsi ruang dan jenis aktifitasnya, sedangkan pembagian depan, tengah dan belakang didasarkan pada tata letak ruang. Wanita menempati daerah belakang dan dalam, sedangkan laki-laki berada pada daerah depan dan samping. Bagian depan sebagai daerah laki-laki, karena laki-laki bersifat di luar, terlibat politik dan hubungan eksternal. Tengah bersifat netral, terbuka bagi laki-laki dan perempuan, sedangkan belakang merupakan daerah perempuan, padaringan dan goah khusus untuk perempuan dan menjadi daerah terlarang bagi laki-laki. Organisasi ruang juga memiliki makna simbolik yang berhubungan dengan tangtungan jelema. Tepas imah merupakan bagian hulu (kepala) mengandung makna manusa ka Gustina, terlihat pada fungsi halaman rumah yang dipakai untuk perayaan berbagai upacara ritual sebagai wujud syukur kepada Tuhan.

Tengah imah berarti awak (badan) memiliki makna kahirupan, terlihat pada fungsi ruang keluarga dan kamar tidur sebagai pusat kegiatan inti (hidup) penghuni, seperti: beristirahat, melakukan hubungan suami-istri, melahirkan, membesarkan anak, bercengkrama dan sebagainya. Pawon adalah suku (kaki) maknanya kabinasaan yang didasarkan pada kepercayaan masyarakat terhadap adat, bahwa apabila seseorang meninggal, maka rohnya berada di pawon selama empat puluh hari, kemudian pindah dan berada di atas suhunan pawon selama tujuh hari. Selama roh berada di pawon, keluarga diharuskan mengirim doa agar yang bersangkutan segera kembali ke Penciptanya.

Komponen bangunan berhubungan dengan simbol tangtungan jelema pada bentuk panggung yang terdiri dari: lelemahan, pangadeg dan suhunan, yang disusun berdasarkan sistem struktur dan konstruksi panggungnya. Ketiga komponen bangunan tersebut dimungkinkan memiliki keterkaitan yang erat dengan pembagian tiga jenis dunia yang dikenal di kalangan Masyarakat Baduy (buana nyungcung, panca tengah dan buana larang). Lelemahan yang berada paling bawah merupakan buana larang, pangadeg yang terletak di tengah-tengah adalah 
buana panca tengah, sedangkan suhunan yang menempati hirarki paling atas merupakan buana nyungcung. Lelemahan merupakan bagian suku memiliki makna kematian, karena identik dengan tanah meliputi: tanah dasar dan pondasi umpak; pangadeg termasuk bagian awak yang mengandung makna kahirupan, terdiri dari: dinding dan lantai, sedangkan suhunan merupakan bagian dari hulu yang mempunyai makna manusa ka Gustina, terdiri dari atap.

Masyarakat kasepuhan pantang menggunakan penutup atap dari bahan tanah (genteng), karena dilarang oleh adat leluhur. Dalam pandangan warga kasepuhan, menggunakan atap genteng sama artinya mengubur diri hidup-hidup, karena hanya orang mati yang pantas di kubur. Di samping itu, menggunakan atap tersebut berarti telah menistakan ibu, karena menurut warga, tanah artinya bumi yang memiliki makna ka indung: "manusa hirup tina saripatina taneuh", artinya manusia hidup dari saripatinya (inti) tanah. Taneuh atau tanah juga memiliki makna kematian. Warga yang menggunakan atap dari genteng akan kabendon (mendapat murka) dari leluhur.

\section{KESIMPULAN}

Permukiman masyarakat Kasepuhan Sinar Resmi memiliki bentuk tatanan yang spesifik sebagai peninggalan dari leluhur (karuhun), tidak hanya dalam aspek fisik, namun juga pada tatanan sosial budayanya. Baik aspek fisik dan sosial budayanya dipengaruhi oleh adanya kepercayaan, religi serta tradisi sebagai manifestasi dari nilainilai ajaran leluhur yang telah berjalan dari generasi satu ke generasi selanjutnya.

Daya dari sosial budaya masyarakat Kasepuhan Sinar Resmi merupakan faktor yang mampu mempengaruhi dan menjaga keberlanjutan tatanan lingkungan permukiman tersebut. Selain dipengaruhi oleh nilai adat tradisi, keberadaan pemimpin adat merupakan faktor penentu, karena pemimpin adat memiliki peranan sangat penting dalam me- nata dan mengatur kehidupan masyarakat. Selain itu kepercayaan masyarakat bahwa pemimpin adat sebagai titisan dari leluhur terdahulu sehingga menjadi sosok yang sangat disegani oleh masyarakatnya. Dengan tetap menjalankan tradisi ritual upacara terutama yang berkaitan dengan kegiatan pertanian, maka kehidupan sosial budaya yang diwariskan leluhur tetap terjaga kelestariannya, dengan beberapa adaptasi sesuai perkembangan lingkungan sosial budayanya.

Wujud tatanan fisik tetap mempertahankan bentuk asli yakni rumah panggung yang merupakan implementasi dari nilai simbolis yang dianut masyarakat kasepuhan. Dalam perkembangannya, ada perubahan hanya dari segi material bangunan yang acapkali sebagai strategi adaptasi terhadap ketersediaan material bangunan yang mulai terbatas, atau akibat meningkatnya status ekonomi masyarakat. Bumi Ageung sebagai rumah dari pemimpin adat, menjadi orientasi arah hadap bagi warganya. Kondisi kontur lahan juga mempengaruhi pola permukiman masyarakat dan memberikan batasan berupa zoning secara vertikal, dimana Bumi Ageung menempati kontur tertinggi. Bumi Ageung menghadap ke arah Selatan dimana dipercaya sebagai tempat hidup dan bersemayamnya Raja Padjajaran yang merupakan leluhur dari masyarakat Kasepuhan Sinar Resmi.

\section{DAFTAR PUSTAKA}

${ }^{1}$ BPS. (Update 2015). Luas Daerah dan Jumlah Pulau, 2002-2014. https:// www.bps.go.id / linkTabelStatis/view/id/1366. (diakses 26 November 2016).

${ }^{2}$ BPS. (2015). Mengulik data Suku di Indonesia.https:// www.bps.go.id/KegiatanLain/view/id/127. (diakses 26 November 2016).

${ }^{3}$ Soedigdo, D., Harysakti, A., Usop, T. B. (2014). ElemenElemen Pendorong Kearifan Lokal Pada Arsitektur Nusantara. Jurnal Perspektif Arsitektur. 9 (1): 37-47. 


\section{Kearifan Lokal Masyarakat Kampung Wisata Kerajinan Tangan di Dusun Rejoso Kota Batu}

Baskoro Azis

${ }^{4}$ Suparmini, Setyawati, S., Sumunar, D. R. S. (2012). Pelestarian Lingkungan Masyarakat Baduy Berbasis Kearifan Lokal. Jurnal Penelitian Humaniora. 18(1):8-22.

${ }^{5} \mathrm{Haba}$, J. (2010). Realitas Masyarakat Adat di Indonesia: Sebuah Refleksi. Jurnal Masyarakat \& Budaya. 12 (2): $255-276$.

${ }^{6}$ Kementerian Perencanaan Pembangunan Nasional. (2013). Masyarakat Adat di Indonesia : Menuju Perlindungan Sosial yang Inklusif. Jakarta: Direktorat Perlindungan dan Kesejahteraan Masyarakat.

${ }^{7}$ Ningrat, A. A. (2004). Karakteristik Lanskap Tradisional, di Halimun Selatan dan Faktor -Faktor yang Mempengaruhinya: Sebuah Studi pada Kampung Kasepuhan di Kesatuan Adat Banten Kidul, Kampung Sinar Resmi, Desa Sirna Resmi, Kecamatan Cisolok, Kabupaten Sukabumi, Jawa Barat. Skripsi. Tidak Dipublikasikan. Bogor: Departemen Agronomi dan Hortikultura, Fakultas Pertanian, Institut Pertanian Bogor.

${ }^{8}$ Permatasari, I., Antariksa \& Rukmi, W.I. 2008. Permukiman Perdesaan Di Desa Trowulan Kecamatan Trowulan Kabupaten Mojokerto. Arsitektur e - journal. 1 (2):77-93.
${ }^{9}$ Bukit, E. S., Hanan, H., Arif Sarwo Wibowo, A. S. (2012). Aplikasi Metode N.J. Habraken pada Studi Transformasi Permukiman Tradisional. Jurnal Lingkungan Binaan Indonesia. 1(1):51-62.

${ }^{10}$ Niswah, Z. K., Adiwibowo, S. (2013). Strategi Nafkah Masyarakat Adat Kasepuhan Sinar Resmi di Taman Nasional Gunung Halimun Salak. Sodality: Jurnal Sosiologi Pedesaan. 1(1): 78-84.

${ }^{11}$ Kusdiwanggo, S. (2016). Konsep Pola Spasial Permukiman di Kasepuhan Ciptagelar. Jurnal Permukiman. 11(1): 43-56.

${ }^{12}$ Nuryanto \& Machpudin, I. (2008). Kajian Pola Kampung dan Rumah Tinggal: Warga Kasepuhan Kesatuan Adat Banten Kidul di Sukabumi-Jawa Barat. Artikel Hasil Penelitian. Bandung: Universitas Pendidikan Indonesia.

${ }^{13}$ Hermanto, Pasya, G. K., Al Muchtar, S. \& Sumaatmadja, N. (2012). Filosofi Hidup Sebagai Basis Kearifan Lokal (Studi Pada Masyarakat Adat Kasepuhan Banten Kidul). Jurnal Gea. 12(1):1-14. 